Special Issue on Longitudinal Methodology, Canadian Studies in Population

Vol. 28(2), 2001, pp 219-248

\title{
Unitary Social Science for Causal Understanding: Experiences and Prospects of Life Course Research
}

\author{
Martin Diewald \\ Gerhard-Mercator-Universität Duisburg \\ Fachbereich 1/Soziologie \\ Duisburg, Germany
}

\begin{abstract}
Longitudinal data are superior to cross-sectional data for explaining social processes. Yet, the existing division of labour in social science is a serious handicap for causal understanding of human behaviour. This is demonstrated in this article with the quite unrelated coexistence of sociological research on life histories and psychological research on individual development. Two examples are discussed: the intergenerational reproduction of social inequalities and the openness versus closedness of labour markets. Though there is an increasing awareness of problems of selectivity and unobserved heterogeneity in conventional social research, statistical modelling of these problems cannot replace the need for transdiciplinary data collection and research.
\end{abstract}


Theoretical Issues - Martin Diewald

\section{Résumé}

Les données longitudinaux sont préférables aux données de période pour expliquer les processus sociaux. Par ailleurs, la division du travail dans les sciences humaines présente un handicap à la compréhension causale des activités humaines. Par exemple, il existe en même temps la recherche sociologique sur les événements de la vie, et la recherche psychologique sur le développement individuel. On considère deux exemples: la reproduction inter-génération de l'inégalité sociale, et l'ouverture ou la fermeture des marchés de main d'oeuvre. Quoiqu'il y ait une plus importante appréciation des problèmes de sélection et de hétérogénéité non-observée dans la recherche sociale conventionnelle, la modélisation statistique de ces problèmes ne peut pas substituer à la collection de données et la recherche transdisciplinaire.

Key Words: GSOEP, GLHS, causal understanding, life course research, inter-disciplinary perspective, control beliefs, individuality, action theory

\section{Introduction}

Compared to cross-sectional studies, longitudinal studies are very expensive in terms of money and time. Yet, the analytical superiority of longitudinal over cross-sectional information is unquestioningly accepted in many disciplines. The establishment of largescale longitudinal surveys in the social sciences during the last two decades in many countries is a success story in itself - though the analytical potential of the existing longitudinal data is still 'greatly under-utilized' (Mayer 1999:1).

In the following pages, I try to make a provisional assessment of such studies, and my view is focussed in several respects. First, my main interest lies in confronting the aim of causal explanation of social phenomena with the design of existing studies. In other words, I raise the question whether these designs are actually able to meet the demand not only to describe but also to understand causes and consequences of social and demographic change. Specifically, I will argue that a new generation of longitudinal studies is needed to pursue this aim, because the analytical potential of existing studies is limited in this respect, not least on the grounds of obsolete disciplinary and methodological boundaries in the social sciences. However, when discussing the shortfalls of current longitudinal survey projects, I do not at all want to detract them from their pioneering merits and overall usefulness. 
Second, it is almost impossible to discuss the whole range of longitudinal studies and their respective rationales. So, I adopt here the theoretical perspective of the life course and the aim of life course research to understand the processes by which social change operates to influence the development and life chances of individuals and by which these developments in turn lead to change of entire social systems.

Third, my experiences reflect mainly the German background in this field, though Iwill not discuss it independent of the international experience. In the case of Germany, I mostly draw on two multipurpose, multi-domain survey projects, which together form the core of ongoing programs of longitudinal research in Germany since the early 1980s. These two are the German Socio-Economic Panel Study (GSOEP) and the German Life History Study (GLHS) of which eight surveys have been conducted up to now. They represent two partly competing, partly complementary strategies of collecting longitudinal survey data.

My line of argumentation is as follows. First, I recall the initial claims and promises of longitudinal survey research in social science. I refer to deficits in the realization of these claims and promises as the existing longitudinal surveys were designed and established. It is crucial for this discussion to confront the ideal of 'unitary social science' with the existing division of labor between the research programs of various disciplines in the field of life course research. To make this rather abstract argument more explicit, I shall refer to two different research questions. That the existing division of labor underlying the design of current longitudinal studies cannot be maintained is first demonstrated for research agenda in the mainstream of classical as well as contemporary sociology, namely the intergenerational reproduction of social inequality. Then I shall give some examples of how the inclusion of a specific psychological concept, namely control beliefs, may enhance our understanding of individual life courses. The last section provides an outlook on some possibilities for future, promising longitudinal study designs beyond the existing surveys.

\section{Life Course Research}

\section{The Claims and Promises of Longitudinal Research}

Longitudinal social research is integrally linked to the study of social change. On various grounds, longitudinal data are much more powerful to capture social change than crosssectional data, even repeated cross-sectional data. ${ }^{1}$ Not least among them is the intended social change, that is, the impact of the state on the life course, and challenges for and consequences of public policy for the better life of people (Mayer and Müller, 1986; Mayer 1997). Therefore, public policy in general, and social policy in particular, is the primary audience for such type of research (e.g. Burkhauser and Smeeding, 1999). Longitudinal social research should uncover the mechanisms by which undesirable outcome could be avoided and favorable outcomes could be reached. Especially in the late sixties and the seventies, the Zeitgeist and social democratic governments in particular were optimistic about their ability to mould a better society (Etzioni, 1968; Zapf, 1996). Therefore, 
government agencies were interested in getting more and better information about how and why the standard and the distribution of material living conditions and subjective quality of life developed, and how they could be shaped by policy making. Thus, almost everywhere in the industrialized countries, the establishment of longitudinal social research was (co-)initiated, or at least (co-) funded by governmental agencies.

The theoretically most ambitious and most comprehensive approach to design such longitudinal surveys is the life course approach. It promises not only to describe but also to explain social phenomena as outcomes of past and ongoing processes at different levels of individual and societal development. In other words, the explicit aim of life course research is to capture the processes by which social change operates to influence the development and life chances of individuals and by which these developments fit into the reproduction and change of whole social systems. In particular, this perspective permits the following advances compared to conventional, cross-sectional information and concepts:

- Instead of single, one-shot measurements of status attainment, class position, or welfare positions at a given time point, which may be more or less stable, more comprehensive lifetime accounts of positions within the system of social inequalities are possible.

- Present living conditions and life events can be traced back to, and, thus, partly explained, by constraints and opportunities in the individuals' past biographies. In this sense, the individual life course has to be understood as a "self-referential, multidimensional process" (Huinink 1995:155).

- The unique 'tools' to do this adequately are measurements of the real time processes in different spheres of the individual life and the mathematical modeling of their interplay. Instead of focusing on normative concepts like life phases or the life cycle, 'multidimensional, parallel time clocks' in the form of several events and durations (e.g. age, labor force experience, firm tenure, marriage time and marriage duration) would reflect successive, parallel, or overlapping processes. These processes, when combined with a cohort design, additionally permit to differentiate between age, period, and cohort effects (e.g., Mayer and Huinink, 1990; Alwin, 1995).

- Old and sterile disjunctions between the aggregate, structural macro world on the one hand and the idiosyncratic or over-generalized micro world of individual action on the other hand may be overcome (Huinink, 1995:56-94; O'Rand, 1996:3; Mayer 1999:4). Life courses are to be seen as results of complex interactions between processes operating at different 'levels' (Huinink, 1995:68) - social institutions, structural constraints and opportunities, individual development, and individual action under conditions of historical change. Especially important for studies in the field of social inequalities and labor markets is the distinction between positions and persons who move between these positions. 
- Insofar as the different life domains and 'levels' included in the analysis touch the research areas of different scientific disciplines, life course research claims to have a transdisciplinary perspective and to overcome fruitless fragmentations in the social sciences and humanities.

In sum, the life course approach should thus be the ideal basis for the concept of causation as a 'generative process' of regularities. This concept was favoured by John Goldthorpe for the social sciences over the inadequate concept of 'causation as robust dependence' and the more rigorous, but too narrow and, for the sociological research questions, often not applicable, concept of 'causation as consequential manipulation.' By 'causation as generative process', Goldthorpe means that observed regularities (instead of idiosyncrasies) are identified as 'effects for which causes have to be discovered' and tested empirically. These empirical tests should be closest to a 'subject-matter' account of actions and interactions of individuals generating the observed regularities in time and space (Goldthorpe, 1998:21-22; see also Esser, 1991; Lindenberg, 1989 for the claims of rational choice theory in general). In the following section, I shall discuss which design of life course research is actually able to meet this demand.

Even life course data do not allow for controlled manipulation, neither of the explananda nor of possible causes. Yet, they at least provide the opportunity to study processes (trajectories, durations) within the lives of particular individuals, or households and families, under different circumstances over time (Wu, 1999:16). 'Changes' in both explananda and causes are, thus, not mere variations across different individuals at a given time, as in cross-sectional studies. But, they are real changes for given unities of observation, such that it is possible to control for (unobserved) conditions other than specific trajectories - common causes for both the explananda and the conditions that may lie 'behind' such trajectories. Technically speaking, new methods of statistical modeling have been developed to control for unobserved heterogeneity and selectivity, but I shall not touch upon this aspect in much detail here.

\section{Interdisciplinary Longitudinal Social Research in Germany: GSOEP and GLHS}

In Germany, the 'big start' (Mayer, 1999:1) of longitudinal studies in social science occurred with the start of the Special Research Unit on "Microanalytical Foundations of Social Policy" at the Universities of Frankfurt and Mannheim in 1979, consisting of researchers in sociology, economics, and the political sciences. This is the scientific context in which both the German Life History Study (GLHS) and the German Socioeconomic Panel Study (GSOEP) developed. The first national surveys of the GLHS started in 1981, and the first wave of the GSOEP in 1984. GSOEP and GLHS represent decidedly different strategies to collect longitudinal social survey data. 
Theoretical Issues - Martin Diewald

\section{The GSOEP}

The German SOcioEconomic Panel Study ${ }^{2}$ is a prospective longitudinal survey based on a random sample of private households, clustered by regions. All 'adults' (16 years and older) in these households are then interviewed annually. From the very beginning two levels of analysis were envisioned in the survey design: the individual and the household, whether one makes use of it or not. New households in the sample come about only if they are established by members of the original households - after leaving the parental home, by marriage, or divorce etc. In these cases, all members of the new households are interviewed. The overall sample size in the year 2000 comprises about 20,000 individuals as members of about 12,000 households.

Although in every panel some information is collected about the timing of events and the duration of current states, the ideal of collecting continuous, uninterrupted life histories in various life domains has not been fulfilled. Additionally, retrospective information about the life course before the first interview is obtained, but compared to the retrospective life courses collected in the GLHS (see below), the information is quite rudimentary.

With the focus on welfare development, information on psychological development is rather scarce and restricted to a few attitudes, values, and domain-specific satisfaction scales. No indicators of abilities, performances, or efforts are available. In this respect the GSOEP is much more restricted than the PSID, where more concepts from social psychology and developmental psychology are included and can be used for explaining social and economic phenomena (see e.g., Duncan and Dunifon, 1998; Dunifon and Duncan, 1998). ${ }^{3}$ It is also important to notice that in the GSOEP there is no information about the development of children before age 16, whereas in the PSID there are several 'child development supplements' to collect developmental information in early life which may be important to explain later life course outcomes.

\section{The GLHS}

The German Life History Study is a retrospective study of individual life courses, that is, all information is gathered at the same time for the past life course beginning with birth. The study consists of random samples of different birth cohorts, which implies that the information can only be representative of the specific birth cohorts included in the study. Thus, while prospective panel studies face a problem of 'period centrism' as long as the period of observation is still short, the GLHS faces the problem of 'cohort centrism.' Even if taken together, the cohorts are not representative of the whole population at a given point in time. A specific problem of long-time retrospective studies is recall errors that may distort the data. Those events that may seem less relevant in the subjective reconstruction of biographies at the time of the interview are liable to be forgotten. 'Less relevant' for subjective biographies, however, does not mean that these events are also less relevant for research questions. 
The retrospective life histories contain time-continuous (at the level of months) life histories of parallel processes in various life domains, normally without interruptions. Reliability of information in long-term retrospective data is best for education and employment history, parental status, marital and fertility history, and family and household composition (Peters, 1988; Dex, 1991). In addition, the possibility of modifying measurement instruments during the observation period, unlike as in panel studies, is excluded - unless introduced by design.

Information about past individual or household income is less reliable. And it is widely accepted that information about past psychological development - such as competences, motivational states, affective states, or beliefs - cannot be retrieved with reasonable reliability (Featherman, 1979; Hannan and Tuma, 1979). This is clearly a domain of prospective observations. As proxies for cognitive competences, sometimes past performances are included in retrospective surveys, such as school marks or performances in tertiary education. It has to be stated, however, that competences and performances are not at all the same, and that confounding the two is theoretically misleading.

\section{Advantages and Disadvantages of GSOEP and GLHS}

To study social change, the differentiation between age, period, and cohort effects is crucial (Mayer and Huinink, 1990; Alwin, 1995). By design, cohort studies are by far the best for disentangling these effects. Because of the non-cohort-design of the GSOEP and because of the less complete data, the estimation of cohort effects is severely restricted in comparison to the GLHS. And the analysis of period effects is limited in prospective panels because of the problem of period centrism for "young" panel studies.

There is no contextual information beyond the individual (GLHS) or household (GSOEP) level in either survey. This carries a lot of weight when access to official data is far from easy (in Germany), especially to obtain fine-graded contextual information at the level of communities, neighborhoods or schools. Therefore, as a rule, a researcher cannot expect to combine the individual survey data with contextual information from other sources later on (as it often possible in the Scandinavian countries).

Furthermore, in both surveys, no data account for the psychological development, except for some values and attitudes. In the case of the GLHS, this is self-evident (see above), whereas in the case of the GSOEP, this is the result of holding social reporting and social accounting of welfare development as the primary rationale for the survey design. Thus, both surveys are facing criticisms in recent state-of-the-art publications on life course research. Suggestions call for a fuller integration of life course research with research on individual development, which have remained as two distinct research traditions in the social sciences (Elder and O'Rand, 1995; Mortimer, 1996; Diewald 1999).

The next two sections argue that both these restrictions (lack of contextual information as well as of information on individual development) hamper not only the comprehensiveness of possible research questions but also the analytical power for the causal explanation of some of the core questions in sociology. It is not simply an argument about incomplete 
Theoretical Issues - Martin Diewald

information or a too 'thin' description of life courses; the standard sociological questionnaires are already overtaxed as single source of information. But the point is that the instruments are often not sufficient to distinguish whether they measure effects of the social environment or of psychological characteristics of acting individuals.

\section{Fallacies in the Design of Existing Survey Designs}

Regarding the question of how 'generative processes' (see the earlier section) must be tested in the social sciences, an increasingly disputed issue is what must be directly observable and, thus, what must be included in the statistical modeling to reconstruct these processes. Especially in the discussion about fruitful linkages between large-scale social surveys and rational choice theory, many social scientists argue against the necessity of including data other than social characteristics and actions (Goldthorpe, 1998:23-25; Ultee, 1996; see also most contributions in Blossfeld and Prein 1998). This shows up mostly as reluctance towards 'subjective data,' i.e. data that relate to individuals' perceptions, evaluations, and orientations, or personality in general (for counter arguments, see Opp, 1998). This reluctance may make sense in the case of cross-sectional information, where there is only correlation without temporal order. In such cases, sociologists may claim that for the understanding of social outcomes, psychological variables are of no use, since it is impossible to decide whether these psychological variables have any independent causal status compared to social structural or institutional factors (Mayer, forthcoming). I will argue in the following that such a strategy is a fallacy if a longitudinal design is available and if the goal is causal understanding. The general exclusion of 'individuality,' mistakenly seen as opposed to 'regularity,' in conventional social studies cannot be justified simply by bringing the 'social' or 'structural' in front against other effects and determinants of human behavior. Sociologists often claim a specific agenda for research on causal understanding by referring to the Durkheimian 'explaining the social by the social.' It is doubtful that Durkheim is really an authority for a strategy of restricting oneself to explain the social only by the social (Albert, 1999:221).

As I develop below, neglecting such information may often mean that standard sociological variables are loaded with too many possible theoretical meanings to be able to represent theoretically unambiguous determinants and effects of human behavior. I make my argument in three steps. First, I point out that the current division of labor in social science is a problem for true causal explanation. Second, I consider the life course approach in a transdisciplinary perspective that takes serious account of the claims and promises discussed earlier. And, third, I take a closer look at the problem of individuality for explanations based on rational choice theory. 
Unitary Social Science for Causal Understanding Toward

Longitudinal Research in the Social Sciences

\section{(1) The historical division of labor in science and factors of causal explanation}

It has been shown convincingly that the present demarcations between the various social science disciplines (sociology, psychology, economics, historical science, anthropology) do not follow so much a problem-focused logic as practical interests of researchers in the past and historical contingencies (Albert, 1999; Wagner, 1991). In other words, there is no clear distinction between different explananda that separate the various social science disciplines from one another. It is often proclaimed that different perspectives on possible explanatory factors are relevant for that. But as I show below, the Durkheimian 'explaining the social by the social' is by no means a powerful denominator to distinguish sociological from psychological explanations.

A problem-focused research perspective, as it is called under the label of 'transdisciplinary' research (Mittelstraß, 1998), should even go beyond the claim of a unitary social science to include also the nomological (not merely historical) explanations of human behavior that are proliferating in the natural sciences, especially in biology with its sub-disciplines (Meier, 1999). Nomological explanations based on biology and evolutionary theory are neither necessarily connected with a rejection of theoretical institutionalism nor of methodological individualism (Albert, 1999:225-228). Rather, they can be successfully combined to give most comprehensive explanations of human behavior and the emergence and development of social institutions (Dux, 1997). Rather than basing explanations on pre-existing, but shaky disciplinary demarcations, problem-focused research designs should try to take into consideration all factors that are relevant for causal understanding. Seen from this angle, thinking in present disciplinary boundaries must be replaced by a distinction between different classes of causal factors that could be more or less relevant for the explanation of specific phenomena.

By adopting an evolutionary perspective, genetic, ecological, and social causal factors can be distinguished (Smith and Szathmáry, 1995; Wieser, 1997). In the following, I limit my argument to the interplay between social and genetic factors. It is important to notice that these causal factors are neither deterministic nor simply additive. Since human beings are equipped with a nervous system including the brain, they are able to relate reflexively to their own behavior and its preconditions. Thus, the nervous system takes over the role of a hinge between the three classes of factors. Actual behavior is then guided by tactical responses to interacting, sometimes even conflicting, bundles of requirements, restrictions, and chances for individual development as they stem from genetic, ecological, or social factors accumulated over time. In this sense, the individual is indeed "co-producer of his or her development" (Lerner, 1984:3), and this perspective provides very straightforward grounds for a reconstruction of individual life courses, as well as institutional and structural developments, from the perspective of individual action (Giddens, 1976; Lindenberg, 1989).

When I refer in the following to the interplay of genetic, ecological, and social causal forces, I do this not in every respect. I leave aside the question of how the genetic code of humans brings about natural selection and common behavioral patterns (see for this discussion, Runciman, 1998). I confine myself instead to the importance of differential 
Theoretical Issues - Martin Diewald

genetics, the differences between individuals in their genetic 'equipment.'

\section{(2) The life course in a transdisciplinary perspective}

At the beginning of life course research, especially in sociology and psychology, also in economics and demography, there were "great expectations that the disciplines involved in this 'life course turn' ... would not only grow together in a parallel trajectory, but there would be co-evolution in the direction of a truly interdisciplinary or even transdisciplinary paradigm on human development" (Mayer, forthcoming: 1). However, even optimists cannot say that this prophecy has come true or at least tends to become true nowadays. Life span psychology and life course sociology diverge not only in regard to the level of the unit of analysis (the major aspect of human lives and the relevant dependent variables) but also appreciably in regard to the broad causal forces, which are seen at work. (Mayer, forthcoming: 8-14). Though there are admittedly some common explananda in sociology and psychology, like values, occupational success, family development, or deviant behavior, life course sociology focuses predominantly on the interplay between different life events in different spheres of life (e.g., marriage, child births, divorce, or job careers) and time-independent social characteristics (e.g., gender, family of origin). The comparison of such life courses for different cohorts and/or societies is intended to unravel the impact of different institutional settings, historical events, and structural opportunities on human lives. Psychological traits and functional capacities of individuals are mostly seen as being 'not social' and thus out of the realm of sociological explanations. This reluctance applies even more to the inclusion of psychological variables as explanatory variables. Whereas it is nice for sociologists to claim that 'psychological' traits are in fact social constructions, the other way round is quite awkward - to admit that what one observes as social characteristics may be shaped by psychological traits and functional capacities, too. And if one accepts or claims that the first proposition is true, then one can quite easily reject the second proposition, because psychological measurements then do not have any independent causal meaning compared to socio-structural factors but only a status as intermediary factor.

In contrast, the psychology of individual development and life span focuses exactly, though not exclusively, on these psychological traits and functional capacities as explananda. The range of phenomena to be included here comprises on the one hand ontogenetic, mainly age-dependent, basic components of psychological functioning: functional capacities like cognitive abilities or speed information processing as well as basic, universal behavioral patterns like control strategies (Baltes, Lindenberger and Staudinger, 1999). On the other hand, a more 'liberal' concept of individual development focuses additionally on parts of the personality which are less determined by biology and age-dependent ontogenesis but formed by culture, social structure, and historical events (Brandstädter, 1984), as is the case with values, perceptions, life goals, self-confidence, and identity. Explanations are based on social as well as biological (especially genetic) 
grounds and evolutionary theories, the mix of them being dependent on the focus of research interest in the entire range between ontogenetic development and sociocultural formation of personality. Thus, developmental psychology is at least in principle more open to the whole range of explanatory factors relevant to explaining human behavior and the shaping of individual life courses. However, its conceptual apparatus and efforts in disentangling the socio-structural explanatory factors as opportunities and constraints for individual development are in practice far less developed than in sociology. Nevertheless, when viewing social factors as defining adaptive tasks for the individual, developmental psychology overcomes the sociological perspective of social forces impinging in a uniform, more or less deterministic way on individual lives and behavior. It allows for specifying the variety of ways in which individuals react to social opportunities and constraints, and how they do this by translating them not only into overt behavior but also into perceptions, beliefs, and goals. Thus, life courses are surely 'products' or 'mirrors' of social institutions, culture, and history (Mayer, 1997) - which is often neglected in developmental psychology - and they are also at the same time the product of individuals as natural organisms, decision-makers and personalities. As 'product' of these forces, individuals cannot be reduced to mere 'puppets.' Besides, modern sociology increasingly adopts the point of view that the binding power of institutions and norms is weakened, thus challenging, and at the same time enabling, the individual to select or develop action orientations and own biographical scripts beyond well-defined patterns and reactions. In other words, action orientations and biographical scripts cannot be simply deduced from social circumstances alone.

The question arises, then, whether this rather unrelated coexistence of sociological life course research and psychological research on individual development characterizes a sensible and useful division of labor. My answer is: No, if we accept that genetic and social causal factors are not separated but intertwined in everything we can observe in individual lives, and that individual decisions do matter. The arguments for this view are visualized in Figure 1:

- Everything we can observe at the individual level at any time is, in theoretical terms, supposed to be an interaction effect of social and genetic influences and individual choices stemming from cumulative processes over time; (almost) nothing of it is purely social or purely genetic in terms of causal understanding. Rutter (1997) provides many illustrative examples of how observed behaviour or individual characteristics are, to different degrees and by different types of causal relationships, caused by different kinds of interactions of genetic and social factors. If one is ready to accept this perspective, a necessary consequence is that in order to study social influences comprehensively, they cannot be separated from an assessment of genetic influences and previous interactions between genetic and social influences - simply because these causal factors are not merely additive.

- This applies to both research agendas existing in the field of life course research - life history studies (mostly situated in sociology) and studies of individual development (mostly situated in psychology). And, it implies that two widespread misunderstandings have to be rejected as guiding principles 
Theoretical Issues - Martin Diewald

Figure 1

The Multi-level/Multi-layer Embeddedness of Individual Development 
for research designs. First, in terms of a generative process, life histories are not per se exclusively 'social' and psychological developments are not

exclusively genetic or 'psychological' as opposed to 'social.' Thus, the Durkheiman 'explaining the social (only) by the social' as a rationale for sociological life course research is misleading when used to exclude psychological concepts from explanation.

- Individual-level measurements cannot be adequate independent measurements of social influences, since all the other causal factors are integrally confounded with such measurements. In this sense, Bronfenbrenner and Crouter (1983) have proposed to call individual attributes - like belonging to a specific social class, or having a certain status - as 'social address' rather than as measurements of the social structure, be it positional structure, or social networks, or collective actors bargaining about stability and change in social systems and offering opportunities and constraints for individual action (see Figure 1). In other words, if we are interested in structural effects, we have problems with identifying them in individual-level data alone.

- Moreover, both research agendas (life histories, individual development), though actually existing quite unconnected side by side, comprise processes that are integrally linked to each other. Therefore, for purposes of causal understanding as a generative process, both streams of development and their interactions have to be taken into account - even if we are only interested in understanding either life histories or psychological developments alone. This may be necessary to avoid ambiguity in the causal meaning of an individual attribute at a given time in terms of a generative process. Suppose, for instance, we want to assess the theoretical meaning of the achieved level of education for some later life course events, such as getting a job in the labor market, income attainment, or leading a successful life in general. The effect of educational degrees may be due to anyone of the following: (1) actual differentials in task-specific abilities, (2) differentials in task-specific abilities assumed by employers, (3) actual differentials in more general abilities like fluid intelligence, or crystallized intelligence represented more or less by differential educational degrees, (4) differentials in more general abilities like fluid intelligence, or crystallized intelligence as perceived by possible employers, (5) institutional rules providing more or less credentials, something like 'planful competence' correlated with amount of education (Clausen 1991), and (6) the differential availability of jobs in different segments of the labor market.

Thus, only analysis of parallel processes of both (sociological) life histories and (psychological) individual development is able to provide a rather complete understanding of society shaping the lives of individuals. Going back to the 'genes' or 'individuality' therefore is desirable, but even without it the parallel analysis of life histories and individual development is useful for both strands of research. The discussion of 'individuality' and individual action in the next section will clarify this argument. 
Theoretical Issues - Martin Diewald

\section{(3) Individuality and individual action}

'Individuality' may be defined as differences in personality, whether they be genetically fixed or acquired and accumulated by different experiences over the life course. At first glance, the term 'individuality' as a relevant aspect of sociological research may contradict the rule formulated above that it is social regularities that have to be the focus of research. This is misleading, however.

- Even if one is less interested in the study of the life course as such than in the functioning of social institutions or systems of social inequalities, the question of nature/nurture interactions is not irrelevant. This is because the assessment of social inequalities as outcomes at the individual level also requires an assessment of existing natural inequalities. Education or employment systems and their historical change can be thought of as being administered to make efficient use of competencies and personality types (Turner, 1988:9) as they are available at different stages of the life course according to selection and adaptation principles formulated, for instance, as meritocracy and skill development. These institutions are thus primarily defined by their selections of people and the selections they initiate as self-selections of individuals according to perceptions and action orientations formed by prior experiences.

- The evolutionary perspective outlined above, and especially the hinge function of the nervous system for "working out adaptations", have two implications for the study of individual decision-making. First, the assumption of stable preferences over time as well as the assumption that all actors have the same preferences cannot be upheld (see Opp, 1998:218-227). Rationales for action do not simply follow a logic of the present situation but are developed by people who are thinking ahead and may learn constantly (Elster, 1989; Burkhauser and Smeeding, 1999:2-3). The standard assumptions of economic 'black box' rational choice theory of actors with constant preferences stem from times when more elaborate psychological action models did not yet exist (Albert, 1999:224). Besides, it does not make sense to reserve the idea of individual choice for overt behavior only, and to conceptualize orientations in all cases as prior to choices. Theories of adaptive coping (Lazarus and Folkman, 1984) or developmental regulation (Heckhausen and Schulz, 1995) make evident that stability or changes in orientations are often alternatives to stability or change in overt behaviors.

- Perceptions and orientations should not be conceived of as being contrasts to structural opportunities and constraints in explaining life course states and events. In a longitudinal perspective - and only in a longitudinal perspective - they are themselves formed by earlier structural forces in interaction with other causal factors. Neglecting them would not lead, as intended, to focus exclusively on 'explaining the social by the social,' but would rather lead to underestimate the importance of 'the social' which is represented in psychological states too. They have double importance as determinants for individual self-selection as well as criteria for selection by collective actors and 
institutions.

- In the case that genetic information as a primary source of individual development and behavior that is relevant for a specific research question is not available (and despite considerable progress in the field this is normally still the case), the generative process should be traced as far back as possible towards genetic determinants. The interaction between the various classes of factors, mediated by individual choices, is a process that follows historical as well individual time clocks. If we want to disentangle the effects of genes and social environments, we have to start as early as possible with the observation of individual lives, if possible at conception, and from then on follow (1) how conditions above the individual level may change, (2) how individuals bring an accumulating history of past life experiences with them to each transition, interpret the circumstances in terms of this legacy, and work out adaptations that can alter their life course (Elder and O'Rand 1995:456).

At this moment, it may be appropriate to recall that hardly any existing data set will meet all the demands formulated in this section. However, the comprehensive life course approach may serve as framework for formulating hypotheses about social mechanisms creating social regularities that may lie behind the correlations found in conventional, longitudinal social survey data. For the future, it may serve as a rationale for amalgamated studies to fill out the black boxes left in usual designs.

The theoretical inclusion of genes as possible explanatory factor may lead to some reluctance against such an approach among social scientists, representing an unlimited and "unqualified demand for explanation" (Ultee, 1996). Or, it may lead to the hint that several statistical procedures now exist that permit control for selection biases and unobserved heterogeneity. Therefore, I wish to demonstrate the need for research designs that follow the arguments presented here by applying these arguments in the next section to a research agenda which is undoubtedly at the heart of the sociological research tradition: the intergenerational reproduction of social inequality.

\section{The Intergenerational Reproduction of Social Inequality and the Life Course}

The common central question of intergenerational mobility and status attainment research asks whether these processes are on the whole 'meritocratic' or not. Meritocracy means, first, that there is a relatively open hierarchical positional structure, and that positions at different levels are in principle filled according to merit differentials by means of competition. There is, however, a second assumption, which is usually linked to the idea of meritocracy: Ascriptive features should not distort the influence of merit on status attainment (or on access to higher classes). In other words, it should be merit and nothing but merit which is relevant in this respect. This second assumption is reasonable since hardly any society can be imagined which is not based on some kind of meritocracy. 
This sounds more straightforward than it is in reality, because it assumes a more or less additive relationship between ascription and merit: Either it is achievement (or merit) that matters, or it is ascription. In reality, however, both are intertwined in mutually generative processes over the life course, and this makes it quite difficult to test for meritocracy or even to define it without ambiguity. As I will show in the following, sociological research usually fails to meet the inherently necessary conditions to test for meritocracy against social advantage or disadvantage represented first of all by the class, status, and/or income of the family of origin. This notion of social advantage or disadvantage implies that some "natural", non-social starting point is needed to define merit as opposed to ascription.

The argumentation starts with the simple question of what 'merit' is. The simplest and at the same time most frequent answer is the formula: ability plus effort, or more literally, "individual talent, hard work, and the determination to succeed" (Bond and Saunders, 1999:245). In any case, it is wrong to equate merit simply with IQ. Relating it to developmental psychology, I propose that it is useful, in the development of 'ability plus effort', to distinguish between (1) a few basic and very general competences (e.g. cognitive speed), (2) more specific competences (e.g., planful action competence, social skills), (3) a multi-level, multi-domain variety of performance (e.g., IQ test scores or verbal ability test scores as particular types of intellectual performance; school marks and achieved level of schooling and training; or context-adequate patterns of perception, interpretation, and taste), (4) the differentiation between different levels of social 'visibility' of performances ${ }^{4}$, and (5) the placement within the class or status hierarchy of a society. This sequence is open to two different definitions of what 'merit' is. 'Merit' as opposed to ascription, as 'natural', 'pre-social' abilities, is restricted to the first, perhaps even the second stage, captured by very early measurements of these competences or genetically sensitive research designs if not by the genes themselves. 'Merit' as something a society must value in order to maintain and advance itself, however, is (visible) performance. Thus, the meritocracy question can be reasonably operationalized by the tension between the two definitions, or better as a lifelong generative process of mutually effective social conditions - which may be more or less advantageous - and performances evolving out of the competences, which also have to become visible in order to have consequences within the system of social stratification.

There is at least one critical point in this chain of transformations in these mutually shaping processes, and this applies to what Bourdieu (1977) has strongly argued: To a lesser degree than cognitive competences, so-called 'soft skills' (such as visible performances like 'cultural capital') are not always 'innocent' performances in the sense that they are directly relevant for the tasks that characterize more or less valued occupations, but are liable to serve social closure instead. This may be true, but I would argue that the observation of whether and how some individuals develop such more context-specific performances (which are at the same time more open to conditions of advantage and disadvantage) out of more basic (and more genetically determined) competences, and others do not, is perhaps the most straightforward way to relate these context-specific performances to the earlier starting point of the development of more general competences. 
However, this is not at all the way in which this question is handled in sociological research on the reproduction of social inequalities. Two main research traditions can be distinguished in this field: (1) the mostly American stream of status attainment research and (2) the mostly European, and especially British, class structuration approach.

In the status attainment tradition, occupational success is most directly seen as the outcome of individual characteristics, namely effort and ability, mediated by educational success. The advantageous or disadvantageous significance of the status of the family of origin is deduced from differential encouragement of children by their parents to perform well at school. It is mostly this influence on effort that is supposed to capture the ascriptive meaning of status of family of origin. Further elaboration of this approach with more detailed life course data break down the linkage between education and occupational status into several single steps (e.g., Kerckhoff, 1995) but do not touch on the linkage between the family of origin and education except family structure and the intergenerational transmission of success aspiration. Sometimes, ability measures like verbal ability or IQ scores are included, but measurements are always collected only after school entry.

This research tradition can be attacked for several reasons. The most common is that it neglects structure (Breen and Goldthorpe, 1999:1-7; Savage and Egerton, 1997:648-649). A 'variable race' between individual factors and 'structural' factors, both measured as individual characteristics, in regression-type analyses is by no way appropriate in order to assess their relative importance in causing social mobility. There are, however, several attempts to include measures of organizational and labor market structures in mobility studies to distinguish between positions and persons allocated to these positions (e.g. Sørensen, 1986a; DiPrete, 1993). These studies are, however, more or less restricted to shed enough light on the connections between educational attainment, first labor force and later labor force placements, and they do not take into account the individual development of competences, performances, or aspirations. In other words, the black boxes of the classical Wisconsin approach are mostly seen as located on the "long way between elementary school and adult social class position" (Mayer 1999:8), but obviously less in the short but important link between social origin and educational attainment.

What consequences does this omission have for answering the question of meritocracy? No less than that 'social origin' as the theoretical starting point of reproduction of social inequality remains theoretically ambiguous in important respects. Since basic competences are genetically inherited to a considerable degree, and more specific competences as well as performances beginning with birth are also socially constructed, natural 'merit' and socially constructed 'merit' evolving out of natural merit cannot be separated. The rigorous and angry sociological criticisms of the 'Bell Curve' by Herrnstein and Murray (1994) that IQ measurements of children are not valid indicators of genetically inherited competences are absolutely correct on several grounds. But on the other hand, it is true that without capturing the reciprocal processes between competence development and its social precursors from the very beginning of individual life, it is impossible to differentiate between the 'innocent' natural differences in competences and the socially constructed development of competences and performances. Therefore, later assessments of IQ and other abilities/competences cannot be contrasted as socially exogenous "merit" against 
social advantages and disadvantages represented by the family of origin. Children from families with higher status or class position are more likely than children from families with lower status or class position to have the kinds of talents and personal qualities which are required in order to achieve success both by genetic inheritance and early socialization.

The other major tradition of research on the intergenerational reproduction of social inequality is the class structuration approach identifying patterns of association between the social class membership of fathers and sons. One big advantage of the class mobility approach is that by separating stability and change in the marginal distributions from total mobility, structural opportunities for mobility can be taken into account without drawing on data sources other than individual survey data. Here again, the same objection regarding the theoretical status of class of origin can be raised: "Finding a clear statistical association between class origins and class destinations, researchers have tended to assume that this is the product of social advantage or disadvantage. The explanation for why they do better on average than working-class children therefore lies in differences in their social environments - their homes, their schools, their peer groups" (Saunders, 1997:261). It is true that Erikson and Goldthorpe (1992), to cite the most prominent representatives of this approach, impute differential properties to individuals according to their class of origin. But again, this theoretically excludes natural competences, and it does not try to differentiate between various social factors linked to class membership more than in a purely additive way. As we have seen, however, it is simply and irrefutably wrong to assign only to parental status/class meanings of socially inherited advantages and disadvantages, as vice versa for pure genetic inheritance. It is not examined empirically whether children from higher classes succeed better due to more parental encouragement, or due to better material living conditions, or due to early learning of middle-class ways of thinking, speaking, and behaving, or due to attending better schools, or finally due to parental networks mobilized to place them in better jobs.

I conclude this section by arguing that (American) sociology got in some way exactly the 'Bell Curve war' it deserved. Why? The sociological research on the reproduction of social inequality for a long time could rely on a 'Zeitgeist,' a societal agreement, that inequalities are essentially if not exclusively socially constructed, a construction which can be designed by public policy, and that natural inequalities do not matter. During this decade, this Zeitgeist has powerfully changed to the disadvantage of affirmative action. It now favors theories that try to identify genetic roots of human behavior. This shift now challenges sociology much more than before to carefully disentangle both kinds of effects. Considerable efforts have been undertaken to do this, but the most painful ambiguity shall remains: What precisely does social status, class position or income situation of the family of origin mean for the intergenerational transmission of social inequality?

The increasing awareness of this problem has not in the least led to a considerable expansion in the use of statistical modeling techniques that take care of selection problems and unobserved heterogeneity. Without doubt, this is a considerable progress, since at least it allows differentiating between purely correlational relationships, which in fact must be traced back to other common background factors, and 'true' relationships. Yet it does not solve well enough the problem of bringing light to the black boxes which hide the 
Unitary Social Science for Causal Understanding Toward

Longitudinal Research in the Social Sciences

generative processes that bring about advantage and disadvantage during the life course, especially in the case that the alternatives to purely correlational relationships are not made clear. $^{5}$

\section{Action Theory, Control Beliefs, and Life Course Events}

Rational-choice theories and action models have gained more and more terrain in sociology and empirical social research (Coleman 1990). This theoretical turn seems to correspond to a socio-historical shift in modern societies from external enforcement by collective pressures, norms and material incentives to more individualization by internal motivation and flexible planning and decision-making (Beck, 1986). When relating to individuals as decision-makers, however, sociologists tend to a concept of the individual actor where motives for action are either universal, like in economics (Lindenberg, 1989), or sufficiently derived from their location in the social structure and system of social inequalities (Goldthorpe, 1998). Deeper understandings of the personality standing behind decision-making, or, in other words, of what constitutes the hinge function of the nervous system for working out adaptations to the environment, are seen as idiosyncrasies that are not relevant to sociological explanation.

Yet, as I argued already in the second section, this demarcation is not at all convincing, since we can learn from an evolutionary perspective that individuals are not only externally driven agents, or 'structural puppets,' but that their capacities and aims as agents are formed by a number of different forces, many of them being social or interacting with social factors. Characteristics of personality belong to these forces. I will demonstrate this in the following by discussing, as an example, the psychological concepts of developmental control and control beliefs. For my argument here I can rather neglect the differences between different control theories.

All theories of developmental control in a broader sense (e.g., Heckhausen and Schulz, 1995; Bandura, 1977; Bandura, 1992; Baltes and Baltes, 1990; Krampen, 1988) follow the basic assumption that individuals want to exert control over their own development either by actively shaping their environment or by adapting one's goals to an environment which is not easily changeable. Control beliefs are convictions about which factors are most relevant for a successful life: external societal conditions (e.g., the educational system or the labor market), internal resources (e.g., IQ, effort, health) or simply chance. Control beliefs may be more or less consistent with actual opportunities and constraints in the educational system, or with actual IQ of the individual; in other words, they are not simply correlates of 'objective' living conditions and life events.

Control beliefs are formed by current social opportunities and constraints, and also by the former life course. Thus, they represent important elements of individual coping with present as well as past social conditions, though they are not simple subjective representations of these present and past social circumstances. And, vice versa, these beliefs structure the individual choices of different control strategies and, thus, the future choice of behavior in addition to these actual opportunities and constraints (Heckhausen 
Theoretical Issues - Martin Diewald

and Schulz, 1995).

My own analyses of the social situation and occupational careers of East Germans of different birth cohorts during the transformation clarify how the inclusion of indicators of individual development into the study of life histories can further the understanding of life courses. In the East German Life Course Study of the Max Planck Institute for Human Development in Berlin, we additionally included a single-point measurement of control beliefs and subjective tenacity and flexibility as different control strategies when collecting information in 1991/92 from the East Germans (of the birth cohorts of 1929-31, 1939-41, 1951-53, and 1959-61) about their retrospective life histories before and after the Berlin wall came down. Though these one-shot measurements are not yet the parallel measurement of life histories and individual development argued for in this article, they can sufficiently demonstrate the potential use of this research strategy. This demonstration applies to the social construction of such beliefs by biographical and socio-historical processes as well as to the impact of such psychological dispositions for later life course outcomes (Diewald 2000).

The examination of how control beliefs, control strategies, and self-esteem varied between different groups of East Germans in 1991/92 showed some unexpected results, which are important to understand the consequences of the East German transformation (Diewald, Huinink and Heckhausen, 1996; Heckhausen, 1999). Psychological theories of developmental regulation predict that control beliefs and control strategies vary with age in a monotonic fashion, and there is a body of empirical research supporting this prediction. Younger adults rely on primary control strategies and control beliefs emphasizing own efforts and abilities. When growing older, secondary control beliefs become more important, and external control conditions are more emphasized. Both strategies are able to maintain self-esteem. However, this general expectation did not hold true for East Germany in 1991/92. The 1939-41 birth cohort displayed the unique combination of a low level of persistence in the pursuit of life goals and a high level of inflexibility in adjusting these goals. One could assume that specifically for this cohort, changing living conditions and a devaluation of formerly accumulated resources led to lower levels of internal control beliefs, primary control, and a lowered self-esteem. Multivariate analyses showed indeed that these losses were partly due to their bad labor market situation now compared to the relatively good career chances they experienced before 1989 as well as compared to the labor market situation of the other cohorts after 1989. The first relates to the fact that due to specific historical circumstances this cohort experienced superior career opportunities in the GDR compared to all younger cohorts. But after 1989, this cohort had fewer opportunities than the younger ones who were better able to accommodate to the requirements of the new labor market. And in the older cohort, those born between 192931 , almost all employees lost their employment due to early retirement schemes that were introduced immediately after the wall came down to relieve the labor market. The oldest group, which had also very good career opportunities in the GDR before 1989, could externalize the reasons for losses after 1989, keep its sense of prior successes, and keep its self-esteem intact. Thus it was for the cohort 1939-41 that devaluation of formerly accumulated resources and investments were highest and opportunities to grasp new chances were lowest among all cohorts. 
By this study, we were able to show that specific historical conditions of sudden societal change (the political transformation) and specific societal conditions situated in time before and after 1989 brought about a situation, where for one age group the usual interplay between possible control strategies could not hold anymore. It is noteworthy, however, that the explanation of cohort-specific differences in control beliefs and control strategies by controlling for social characteristics and life course events like career mobility before 1989 , career mobility after 1989, gains and losses in the sphere of family and social networks, and other covariates like affiliation to the communist party, was only partly successful. Even beyond differences between cohorts in these respects, there remained differences in control beliefs between cohorts. This points to a collective, comprehensive loss of future perspectives for this cohort, which cannot be fully explained even by quite detailed sociological information.

Loss of control is not only an important indicator of quality of life but relevant to a variety of life course decisions and events sociologists are interested in. Individuals with a high level of self-efficacy or high internal control beliefs are better discerners and users of information, have more advantages from social support, they tend to be more optimistic about the success of their own efforts and abilities, and they tend to use these comparative advantages to reach advantageous positions which further strengthen their sense of control. Perceived control can therefore be seen as a product of prior experiences in the society as well as a psychological resource leading to a more active and persistent problem solving behaviour when confronted with stressors.

It would be short sighted, however, to see such beliefs as individual characteristics only. The question is to which degree these specific action competences reflect not only individual traits and resources but also "institutionalized ways of thinking" (Douglas, 1986:63) in a specific society in the sense that social structure is shaping individual behaviour by generating interests and predispositions. For example, Sørensen (1986b) points to the seminal, ideal-typical difference between open-and-closed-position systems. These provide different opportunities and constraints for individual achievement strivings, and they define different mechanisms to obtain the achievement goals. Much more than in closed-position systems, career patterns in open-position systems should reflect a development of individual strivings and capacities. But, "in closed-position systems, it is structure that creates success and failures, efficacy and depression" (pp. 196). Therefore, especially in open-position systems, the certificates and occupational positions held by an individual should reflect individual agency and an unfolding of individual competences. It is mostly in closed-position systems that we find individual competences developing to a high degree in person-situation interactions outside or even against the formal institutions of education and occupation. Thus, when looking at the impact of control beliefs on occupational careers (Diewald, 2000), my interest was primarily on the assessment of how open or closed the East German labour market was for individual effort and ability after 1989.

To summarize, I found different control strategies having only weak or intermediate correlations with failure and success at the labor market after 1989. This is an unexpected 
result, since a system transformation should create an almost open situation. But, as I have demonstrated elsewhere in detail (Diewald, 1999; Mayer, Diewald and Solga, 1999), this is less surprising in view of the overwhelming impact of legislative and other rulings of the East German transformation, leading to immediate and irreversible mass unemployment on the one hand and much occupational stability on the other.

\section{Conclusion: \\ The Need for Transdisciplinary and “Amalgamated" Study Designs}

I have strongly argued for linking life histories to individual development (including in particular the multi-step conversion and differentiation of natural competences into visible performances) to solve problems of causal explanation in the field of intergenerational transmission of social inequality. The advantages of this strategy are threefold. First, it is both theoretically and empirically the best way of filling the gap between family of origin and school enrollment, where the selection and adaptation processes by formal institutions can hardly be the key to study societal selection processes, simply because there are not many processes of selection. Second, it provides the necessary theoretical link between 'natural' inequalities and the social definition and formation of inequalities in competences. And third, also during later childhood, adolescence, and adulthood, it provides the necessary link to the understanding of the selection and adaptation processes of institutions and organizations.

As the example of control beliefs has shown convincingly, the inclusion of personality characteristics is not merely for disentangling the interplay between life histories and individual development. Assessing the formation and the impact of personality characteristics or later life course outcomes is crucial for describing the institutional systems of societies.

It should have become clear that the classical justification for present practices, namely to explain social phenomena (only) by social facts, is non tenable in light of the fact that genetic, ecological, and social factors are not additive to one another but intertwined in reciprocal, mutually shaping relationships. This does not only make it questionable to reduce the study design to standard sociological information if causal explanation by generative processes is the primary research goal. In this sense, the causal meaning of information collected in one strand of life course research - whether life histories or individual development - may often be ambiguous in itself. This applies not only for explananda but also for explanatory factors. IQ scores are obvious examples (often used as proxy for genetically and/or socially inherited ability), as well as educational degrees (often used as indicators of ability, performance, or credentials).

Looking at the international situation in this field, the US and Great Britain seem to be far better off than Germany and France. As I mentioned in the second section, especially in the United States social surveys exist which include test scores of different kinds, like IQ, school marks, or measures of verbal ability. For instance, the PSID includes now some 
information on child development and psychological scales of developmental regulation. And both in the US and in Great Britain there exist life course studies that start during childhood, like the NYLS or the NCDS, which do not exist in most other countries. Even these studies fail, however, in studying the very early formation in life and, thus, the causal meaning of the family of origin. But even all these positive examples are still far away from taking life courses and psychological development seriously as parallel, interdependent bundles of processes forming human lives.

The other source of ambiguity of causal meaning in standard social surveys is the missing contextual information, like neighborhood contexts, organizational ecologies, social networks beyond the respondent's interpretation, or national institutional arrangements. Research has made considerable progress during the last decade in combining individual level quantitative data at different levels, including qualitative data or experimental designs, and in promoting international comparisons (Burkhauser and Smeeding, 1999:2628; Hill and Duncan, 1999; Mayer, 1997).

Thus, classical longitudinal social surveys are important for causal understanding, but usually they overtax their explanatory power if they have to bear the burden of substantive causal explanation all alone. What we need now is a greater integration of psychological and sociological concepts, starting as early as possible in life, and in the future the readiness to integrate natural and social science research designs as well.

\section{End Notes:}

1. For a general discussion see, for instance, Blossfeld and Rohwer, 1995: ch.1; Mayer and Huinink, 1990; Alwin, 1995. For several illustrative examples in the field of income and poverty dynamics, see Burkhauser and Smeeding, 1999.

2. The longitudinal survey programs, which are most similar to the GSOEP in the AngloSaxon world, are the PSID in the US and the BHPS (British Household Panel Project) in Great Britain.

3. In up to now three waves (1994 to 1996), however, at least a simple collapsed scale for measuring control beliefs has been included, focusing on the distinction between internal and external control beliefs (Krampen, 1987, 1988). Control beliefs refer to convictions about whether own ('internal') competences and resources or 'external' social conditions and luck are most relevant for life course failures and successes.

4. Tilly and Tilly (1998:201) as well as Kerckhoff (1995:488) argue that it is exactly visible performance and not performance or ability per se which is relevant for occupational and educational success.

5. Nor is the effect of "true" causal variables per se understood as 'generative process.' 
Theoretical Issues - Martin Diewald

\section{References:}

Albert, H. 1999. Die Soziologie und das Problem der Einheit der Wissenschaften. Kölner Zeitschrift für Soziologie und Soziapsychologie 51: 215-231.

Alwin, D. F. 1995. Taking Time Seriously: Studying Social Change, Social Structure, and Human Lives, in P. Moen, G. H. Elder, K. Lüscher (eds.). Examining Lives in Context. Washington: American Psychological Association. Pp. 211-262.

Baltes, P. B., Baltes, M. M. 1990. Psychological perspectives on successful aging: The model of selective optimization with compensation, in Baltes, P. B., Baltes, M. M (eds.). Successful Aging. Perspectives from the Behavioral Sciences. New York: Cambridge University Press. Pp.1-34.

Baltes, P.B., U.M. Staudinger, U. Lindenberger. 1999. "Lifespan Psychology: Theory and Application to Intellectual Functioning," Annual Review of Psychology 50: 191-215.

Bandura, A. 1992. Exercise of personal agency through the self-efficacy mechanism, in Ralf Schwarzer (ed.): Self-efficacy: Thought control of action. Washington D.C.: Hemisphere Publications. Pp.3-38.

Bandura, A. 1977. "Self-efficacy: Toward a unifying theory of behavioral change," Psychological Review 84: 191-215.

Blau, D. 1999. "The Effect of Income on Child Development," The Review of Economics and Statistics 81: 261-277.

Blossfeld, H. P., G. Rohwer. 1995. Techniques of Event History Modeling. Mahwah, NJ: Erlbaum.

Blossfeld, H.-P., G. Prein (eds.). 1998. Rational Choice Theory and Large-Scale Data Analysis. Boulder, CO: Westview Press.

Bond, R., P. Saunders. 1999. "Routes of success: influences on the occupational attainment of young British males," British Journal of Sociology 50: $217-249$.

Bourdieu, P. 1977. Outline of a Theory of Practice. Cambridge: Cambridge University Press.

Brandtstädter, J. 1984. "Action Development and Development through Action," Human Development 27: 115-118.

Breen, R., J. H. Goldthorpe. 1999. "Class inequality and meritocracy: a critique of Saunders and an alternative analysis," British Journal of Sociology 50: $1-27$. 
Unitary Social Science for Causal Understanding Toward

Longitudinal Research in the Social Sciences

Bronfenbrenner, U. and A.C. Crouter. 1983: The Evolution of Environmental Models in Developmental Research, in: P. H. Mussen (ed.), Handbook of Child

Psychology: Vol. 1. History, Theory, and Methods. New York: Wiley. Pp. 357-

414.

Brüderl, J., A. Diekmann, H. Engelhardt. 1997. „Erhöht eine Probeehe das Scheidungsrisiko? Eine empirische Untersuchung mit dem Familiensurvey, “ Kölner Zeitschrift für Soziologie und Sozialpsychologie 49: 205-222.

Burkhauser, R. V., T. M. Smeeding. 1999. Panel Data and Public Policy. National and Cross-National Perspectives. Paper presented at the Institute for Social and Economic Research 10th Anniversary Conference at The University of Essex, Wivenhoe Park, England.

Cameron, S. C., J. S. Heckman. 1998. "Life Cycle Schooling and Dynamic Selection Bias: Models and Evidence for Five Cohorts of American Males," Journal of Political Economy 106: 262-333.

Clausen, J.S. 1991. "Adolescent Competence and the Shaping of the Life Course," American Journal of Sociology 96: 805-842.

Coleman, J. 1990. Foundations of Social Theory. Cambridge, Mass./London: Harvard University Press.

Dex, S. 1991. The Reliability of Recall Data: A Literature Review. Working Papers of the ECRS Research Centre on Micro-Social Change, Paper 11. Colchester: University of Essex.

Diewald, M. 2000. Continuities and Breaks in Occupational Careers and Subjective Control: The Case of the East German Transformation, in R. Silbereisen and J. Bynner (eds.): The Effect of Adverse and Challenging Circumstances on Life Course Trajectories in the New Germany and England. London:McMillan. Pp. 239-267.

Diewald, M. 1999. Entwertungen, Umwertungen, Aufwertungen. Ostdeutsche Erwerbsverläufe zwischen Kontinuität und Wandel. Habilitationsschrift, FU Berlin, Fakultät für Sozial- und Politikwissenschaften.

Diewald, M., J. Huinink and J. Heckhausen. 1996. "Lebensverläufe und Persönlichkeitsentwicklung im gesellschaftlichen Umbruch: Kohortenschicksale und Kontrollverhalten in Ostdeutschland nach der Wende," Kölner Zeitschrift für Soziologie und Sozialpsychologie 48: 219-248. 
Theoretical Issues - Martin Diewald

DiPrete, T. 1993. "Industrial Restructuring and the Mobility Response of American Workers in the 1980s, "American Sociological Review 58: 74-96.

Duncan, G., J. Brooks-Gunn (eds.). 1997. Consequences of Growing Up Poor. New York: Russell Sage Foundation.

Duncan, G., R. Dunifon. 1998. “' 'Soft skills' and long-run labor market success,” Research in Labor Economics 17: 123-149.

Dunifon, R., G. Duncan. 1998. "Long-run effects of motivation on labor-market success," Social Psychology Quarterly 61: 33-48.

Douglas, M. 1986. How Institutions Think. Syracuse, NY: Syracuse University Press.

Dux, G. 1997. Subjekt und System, Plädoyer für eine historisch-genetische Theorie, in Tamás Meleghy et al. (eds.): Soziologie im Konzert der Wissenschaften. Zur Identität einer Disziplin. Opladen: Westdeutscher Verlag. Pp.147-158.

Elder, G. H., A. M. O'Rand. 1995. Adult Lives in a Changing Society, in K. S. Cook, G.A. Fine and J. S. House (eds). Sociological Perspectives on Social Psychology. Boston et al.: Allyn and Bacon. Pp.452-475.

Elster, J. 1989. Solomonic Judgements. Cambridge: Cambridge University Press.

Erikson, R., J. Goldthorpe. 1992. The Constant Flux - A Study of Class Mobility in Industrial Societies. Oxford: Oxford University Press.

Esser, H. 1991. Alltagshandeln und Verstehen: Zum Verhältnis von erklärender und verstehender Soziologie am Beispiel von Alfred Schütz und "Rational Choice". Tübingen: Mohr.

Etzioni, A. 1968. The active society: a theory of societal and political processes. London: Collier-Macmillan.

Featherman, D.L. 1979. "Retrospective Longitudinal Research: Methodological Considerations," Journal of Economics and Business 32: 152-169.

Giddens, A. 1976. New Rules of Sociological Method. London: Hutchinson.

Goldthorpe, J. H. 1998. Causation, Statistics and Sociology. Twenty-Ninth Geary Lecture, Oxford: Nuffield College.

Grundmann, M. 1992. Familienstruktur und Lebensverlauf. Frankfurt a. Main: Campus. 
Unitary Social Science for Causal Understanding Toward

Longitudinal Research in the Social Sciences

Hannan, M. T., N. B. Tuma. 1979. "Methods of Temporal Analysis," Annual Review of Sociology 5: 303-328.

Heckhausen, J. 1999. Developmental regulation in adulthood: Age-normative and sociostructural constraints as adaptive challenges. New York: Cambridge University Press.

Heckhausen, J., R. Schulz. 1995. “A Life-Span Theory of Control,” Psychological Review 102: 284-304.

Hemishpere. B.U. 1986. Risikogesellschaft. Aufdem Weg in eine andere Moderne. Frankfurt am Main: Suhrkamp.

Herrnstein, R., C. Murray. 1994. The Bell Curve. New York: Free Press.

Hill, M. S., G.. J. Duncan. 1999. Generating New Insights from Longitudinal Research. Paper presented at the Institute for Social and Economic Research 10th Anniversary Conference at The University of Essex, Wivenhoe Park, England.

Huinink, J. 1995. Warum noch Familie? Zur Attraktivität von Partnerschaft und Elternschaft in unserer Gesellschaft. Frankfurt am Main/New York: Campus.

Kerckhoff, A.C. 1995. Social Stratification and Mobility Processes: Interaction between Individuals and Social Structures, in: K. S. Cook, G. A. Fine, J. S. House (eds.). Sociological Perspectives on Social Psychology. Boston et al.: Ally and Bacon. Pp. 476-496.

Krampen, G. 1988. "Toward an Action-Theoretical Model of Personality," European Journal of Personality 2: 39-55.

Krampen, G. 1987. Handlungstheoretische Persönlichkeitspsychologie. Göttingen: Hogrefe.

Lazarus, R. S., S. Folkman. 1984. Stress, Appraisal, and Coping. New York: Springer.

Lerner, R. M. 1984. On the Nature of Human Plasticity. Cambridge et al.: Cambridge University Press.

Lindenberg S. 1989. "Social Production Functions, Deficits, and Social Resolutions," Rationality and Society 1: 51-77.

Mayer, K. U. forthcoming. The sociology of the life course and life span psychology diverging of converging pathways? Manuscript to be published in U.

Lindenberger and U. Staudinger (Eds.), Understanding Human Development.

Dordrecht: Kluver 
Theoretical Issues - Martin Diewald

Mayer, K. U. 1999. 10 Years British Household Panel Project, 15 Years German SocioEconomic Panel and 20 Years German Life History Study - An Interim Assessment of Longitudinal Studies from a Perspective of Life Course Research. Berlin: Max Planck Institute for Human Development.

Mayer, K. U. 1997. "Notes on a Comparative Political Economy of Life Courses," Comparative Social Research 16: 203-226.

Mayer, K. U., M. Diewald and H. Solga. 1999. Social Change and Transformation Findings and Lessons from the East German Case.

Acta Sociologica 42:35-53.

Mayer, K. U., J. Huinink 1990. Alters-, Perioden- und Kohorteneffekte in der Analyse von Lebensverläufen oder: Lexis ade? in K. U. Mayer (ed.), Lebensverläufe und sozialer Wandel, Sonderheft 31 der Kölner Zeitschrift für Soziologie und Sozialpsychologie. Opladen: Westdeutscher Verlag. Pp. 442-459.

Mayer, K. U., W. Müller 1986. The State and the Structure of the Life Course, in A. B. Sørensen, F. E. Weinert, L. R. Sherrod (eds.). Human Development: Interdisciplinary Perspectives. Hillsdale, NJ: Erlbaum. Pp. 217-245.

Meier, H. 1999. “The Challenge of Evolutionary Biology,” Social Science Information 38: $355-365$.

Mittelstraß, J. 1998. Interdisziplinarität oder Transdisziplinarität? in Mittelstraß, J., Die Häuser des Wissens. Frankfurt am Main: Suhrkamp. Pp. 29-48.

Mortimer, J. T. 1996. Social Psychological Aspects of Achievement. Pp.17-36 in A. C. Kerckhoff (ed.). Generating Social Stratification. Toward a New Research Agenda. Boulder, CO., Oxford: Westview Press.

Opp, K. D. 1998. Can and Should Rational Choice Theory Be Tested by Survey Research? The Example of Explaining Collective Political Action, in H.-P. Blossfeld, G. Prein (eds.), Rational Choice Theory and Large-Scale Data Analysis. Boulder, CO, Oxford: Westview Press. Pp. 204-230.

O'Rand, Angela. 1996. Structuration and Individualization: The Life Course as a Continuous, Multilevel Process, in Alan C. Kerckhoff (ed.), Generating Social Stratification: Toward a New Research Agenda. Boulder, CO: Westview Press.

Peters, H. E. 1988. "Retrospective Versus Panel Data in Analyzing Lifecycle Events," The Journal of Human Resources 23: 488-513. 
Unitary Social Science for Causal Understanding Toward

Longitudinal Research in the Social Sciences

Runciman, W.G. 1998. "The selectionist paradigm and its implications for sociology," Sociology 32:163-188.

Rutter, M. 1997. "Nature-Nurture Integration. The Example of Antisocial Behavior," American Psychologist 52: 390-398.

Saunders, P. 1997. "Social Mobility in Britain: An Empirical Evaluation of Two Competing Explanations," Sociology 31: 261-288.

Savage, M., M. Egerton 1997. "Social Mobility, Individual Ability and the Inheritance of Class Inequality," Sociology 31: 645-672.

Shea, J. 1997. Does Parent's Money Matter? NBER Working Paper nr. 6026.

Smith, J. M., E. Szathmáry. 1995. The Major Transitions in Evolution. New York: Freeman.

Sørensen, A. B. 1986a. Theory and Methodology in Social Stratification. In: Ulf Himmelstrand (ed.): Sociology: From Crisis to Science? London: Sage.

Sørensen, A. B. 1986b. Social Structure and Mechanisms of Life-Course Processes, in A. B. Sørensen, F. A. Weinert and L. R. Sherrod (eds.): Human Development and the Life Course: Multidisciplinary Perspectives. Hillsdale, London: Erlbaum. Pp.177-197.

Tilly, Chris, Charles Tilly 1998. Work under Capitalism. Boulder and Oxford: Westview Press.

Turner, R. H. 1988. "Personality in Society: Social Psychology's Contribution to Sociology," Social Psychology Quarterly 51: 1-10.

Ultee, W. C. 1996. “Do Rational Choice Approaches have Problems?," European Sociological Review 12: 67-179.

Wagner, P. 1991. Social Sciences and Modern States: National Experiences and Theoretical Crossroads. Cambridge: Cambridge University Press.

Wieser, W. 1997. Vernetzte Systeme, autonome Teile. Biologische Wurzeln von Bindung und Freiheit. Merkur 51: 84-90.

Wu, L. L. 1999: Turbulence During Early Life: Consequences for Selected Early Adult Transition. University of Wisconsin-Madison.

Zapf, W. 1996. Die Modernisierungstheorie und unterschiedliche Pfade der gesellschaftlichen Entwicklung. Leviathan 24: 63-77. 